$1-1-2005$

\title{
Heritage/Community Language Education: US and Australian Perspectives
}

Nancy H. Hornberger

University of Pennsylvania, nancyh@gse.upenn.edu

Follow this and additional works at: https://repository.upenn.edu/gse_pubs

Part of the Bilingual, Multilingual, and Multicultural Education Commons

\section{Recommended Citation}

Hornberger, N. H. (2005). Heritage/Community Language Education: US and Australian Perspectives.

Retrieved from https://repository.upenn.edu/gse_pubs/10

Copyright Multilingual Matters. Reprinted from International Journal of Bilingual Education and Bilingualism, Volume 8, Issue 2\&3, 2005, pages 101-108.

This paper is posted at ScholarlyCommons. https://repository.upenn.edu/gse_pubs/10

For more information, please contact repository@pobox.upenn.edu. 


\section{Heritage/Community Language Education: US and Australian Perspectives}

Disciplines

Bilingual, Multilingual, and Multicultural Education

\section{Comments}

Copyright Multilingual Matters. Reprinted from International Journal of Bilingual Education and Bilingualism, Volume 8, Issue 2\&3, 2005, pages 101-108. 


\title{
Introduction \\ Heritage/Community Language \\ Education: US and Australian Perspectives
}

\author{
Nancy $\boldsymbol{H}$. Hornberger \\ University of Pennsylvania, Philadelphia, PA, USA
}

Neither this special issue nor the US-Australian dialogue it represents would ever have come into being had it not been for the vision and effort of Professor Russell N. Campbell (1927-2003) and it is to his memory that this volume is dedicated, with gratitude and affection.

As part of the US Heritage Language Initiative sponsored in its initial phase by the Center for Applied Linguistics and the National Foreign Language Center (Brecht \& Ingold, 1998), a series of meetings and conferences were convened, beginning with the First National Conference on Heritage Languages in America, held in Long Beach, California in summer 1999 (Peyton et al., 2001; Wiley \& Valdés, 2000) and ending with the Second National Conference on Heritage Languages in America, held in the Washington DC area in the fall of 2002. Accompanying and supplementing these larger conferences, Russ Campbell organised three smaller dialogue conferences, designed to bring together a select group of scholars specialising in heritage language education (HLE) to inform each other about, reflect on and formulate research priorities that could assist in advancing HLE in the USA and elsewhere. The first of these meetings gathered about a dozen US scholars at Professor Campbell's own University of California at Los Angeles (UCLA) in the fall of 2000 (UCLA, 2001) and the third again convened about a dozen scholars, a day before the Second National Conference, for a focused dialogue on the 'intergenerational transmission of heritage languages' (Campbell \& Christian, 2002).

In the intervening year, on 17-19 July 2001, a bilateral USA-Australia dialogue meeting of nearly two dozen scholars took place in Melbourne, Australia, under the sponsorship of UCLA and the Victoria University of Technology, Melbourne with additional support from Multilingual Matters, which we here gratefully acknowledge. For this effort, Russ teamed up with his colleague Helen Borland of Victoria University, who jointly organised and most graciously hosted the event. It is a selection of papers from that working conference that is featured here.

In addition to organisers Borland and Campbell and the contributors to this volume, additional participants in the Melbourne conference included Richard Brecht, Donna Christian, Michael Clyne, Joseph Lo Bianco and Howard Nicholas, as well as several observers and notetakers. Each invited participant prepared a short paper circulated in advance and the three meeting days were 
devoted to dialogue and development of research questions, priorities and recommendations.

Early in our conversations and throughout the three days, we adopted the convention of referring to our topic as 'heritage/community language education' (HCLE), employing the composite term 'heritage/community language' (HCL) in recognition of the fact that, while scholars and educators in the USA had relatively recently turned to the term heritage language (HL) as a neutral and inclusive alternative to the terms minority, indigenous, immigrant, ethnic, second or foreign language, Australian policy and practice had for at least a decade been using the term community language (CL) to refer to this same range of language resources in their national context. While we were all aware of the shortcomings and ambiguities of either term (about which more will be said in the papers which follow), and commented frequently on them, individual authors may still refer to one or the other in their papers below, in keeping with the literature they draw on or the audience they generally address. We found it useful to identify our common ground with the composite term, which will also appear in the papers below.

The original papers fell out into four categories of issues in relation to developing, implementing, and evaluating HCLE, roughly: communityidentity-culture, policy-ecology-teacher education, programme-curriculum, and assessment-census-survey. These in turn served as rubrics for working groups on the final day, to generate the research recommendations included at the end of this introduction (see below).

\section{Overview of Volume Contents}

These same four categories also became the organising rubric for the present volume, here linked to my continua of biliteracy framework (Hornberger, 1989, 2003; Hornberger \& Skilton-Sylvester, 2000). The notion of biliteracy is useful here, as HCLE is by definition about developing heritage language learners' biliteracy in both the dominant societal language and the heritage language, whether these be indigenous, immigrant, ethnic, second or foreign languages in any particular context. The continua model offers a framework for describing, analysing and interpreting key issues in that endeavour (Hornberger \& Wang, in press). The framework consists of four sets of three intersecting continua each, comprising the content, context, media and development of biliteracy.

We open the volume with two papers addressing issues of community and identity, essential aspects of the content of biliteracy. As Skilton-Sylvester (1997) showed, what biliterate learners read and write about is compellingly important, at least as much or more so than how (media), when (development) or where (context) they do so. Helen Borland's informative account of multiyear, ongoing action research to raise intergenerational awareness and use of the heritage language in Melbourne's diasporic Maltese community, as a means of addressing Maltese youth's academic underachievement, illustrates and confirms what the continua of biliterate content suggest: that heritage language learners who engage in reading/writing contextualised, vernacular content expressive of their own ethnic identity and heritage will be more 
highly motivated and competent to succeed academically and in their broader participation in society. Anne Pauwel's review of the role of the family in community language maintenance and her plea for more research on the role of adolescents in that maintenance likewise draws attention to issues of identity and community; she notes that as the centre of adolescents' social life moves from family to friends and school, they may actively resist or rebel against using the HCL, except in the case of ethnospecific friendship groups.

The following three papers take us to three different regional contexts of HCL biliteracy in Australia, offering a micro to macro level look at the degree to which HCLs are brought into the schools as subject and medium of instruction, i.e. at the particular oral-literate, monolingual-bilingual mix of languages and varieties in use in and out of schools in these contexts. Richard Baldauf provides an overview of community language teaching in the secondary schools with a focus on New South Wales; and Antonio Mercurio \& Angela Scarino do the same with a focus on South Australia. Both of these papers highlight the complex ecology of CLs in the region, the role of policy in fostering CLE in the schools, and the ongoing struggle for curricular and administrative legitimacy of CL teaching and teachers. Christine Nicholls takes us to the Northern Territory and the struggle for indigenous bilingual education there. Nicholls' account of indigenous language dispossession and symbolic violence, inherent in the dismantling of bilingual programmes and failure to offer a clear and viable alternative in their place, serves as a bridge from the community and identity themes of the continua of biliterate content (above) to the programmatic and curricular concerns reflected in the continua of biliteracy media (next).

Michele de Courcy addresses political, sociolinguistic and administrative issues around the choice of languages and literacies as media of instruction in bilingual programmes - for Australian Aboriginal, Italian-background and Deaf students, respectively; among the biliteracy media-related curricular issues raised in these cases are questions of sequencing and exposure to the languages in instruction (in the Aboriginal bilingual programmes), the handling of standard and nonstandard varieties (of Italian), and the fit between scripts and language structures (in the case of Australian sign language and English). Richard Tucker proposes that the two-way bilingual programme, with its relatively balanced programmatic structure for allocating two or more languages and literacies as media of instruction in HCLE, may offer an effective vehicle for the goals of fostering the development of bilingual proficiency, bicultural competence and subject-matter knowledge for Puerto Rican students in Puerto Rico. His paper also emphasises that in order for policy makers and researchers to do a better job of planning and evaluating different instructional and programmatic alternatives for Puerto Rican and other HL students in general, there is a pressing need for more appropriate measures of HL proficiency and use, a point which introduces the assessment and proficiency themes of the last section of the volume.

Policy makers, educators and researchers alike recognise the need for valid assessment measures of heritage/community language learners' language proficiency in order to gauge their biliteracy development and make decisions about programmes, resources, outcomes, etc. Catherine Elder evaluates an 
evaluation experience in four heritage language bilingual programmes in two primary and two secondary Australian schools in Victoria. She identifies a range of biliteracy media, content and context-related complexities in choosing, administering and interpreting pre- and post-tests in these programmes, cautioning that tests should not be used as sole indicators of programme effectiveness nor as adequate measures of genuine learning. In a quite different case, of adult Russian HL learners in the USA, Olga Kagan advocates using these heritage students' biographical data (e.g. age at immigration, family relationships and attitudes toward assimilation, personal interests or aspirations) to group them according to language proficiency level and thereby gear instruction more closely to their needs. Her concern with, for example, teaching HL learners case structure as a whole rather than piecemeal since they already comprehend and use the cases in most discourse situations, instantiates the continua of biliterate development in its recognition that biliterate learners draw on oral and receptive use of their HL as well as written, productive use of English, in their learning.

Terry Wiley concludes the volume with reflections on challenges and discontinuities facing the field of HCLE, as represented in the papers collected here. Highlighting both similarities and differences in the US and Australian contexts, Wiley brings us back to exactly what Russ Campbell had envisioned for these meetings: the opportunity to learn from each other's accomplishments and shortcomings, in order to advance HCLE in these two large 'English-speaking' nations so incredibly rich with diverse heritage/community language resources. It is my hope that our dialogue, as documented here, will serve in that important undertaking which Russ so passionately urged on us.

\section{Melbourne Working Group Recommendations}

\section{Community Group (Borland, Nicholas, Pauwels, Wiley plus Kipp, DeFazio, Mphande)}

New identities emerge in new contexts, and identity is fluid. The negotiation and renegotiation of identity is an area warranting further research.

An area identified as being one of potential collaboration: cross-national comparisons of groups that could also address questions of the intersection between 'national' and 'ethnic identity' - this could enable exploration of how national ethos as well as other aspects of the 'national' context intersect with 'community' identity and would enable consideration of the role of the state in supporting language practices within particular communities. Comparative work would need to consider language groups where the comparison is meaningful in terms of the period of migration etc. - some suggested groups: Vietnamese, Cantonese, Arabic, indigenous languages.

Given the importance of the adolescent years it was agreed that there was potential for further exploration of the place of language in adolescent identity, and how this changes/is renegotiated through adolescence. Ethnographic research would be valuable (similar to Rampton's recent study) and should include consideration of technology and popular culture in these processes. 
Such studies and comparative work could benefit by considering factors such as gender and the role of the presence or absence of adult role models (e.g. Somali youth in Australia currently) in such identity negotiation and renegotiation.

\section{Policy and Teacher Education Group (Baldauf, Hornberger, LoBianco, Nicholls, Chen)}

Research Recommendation One

We propose that a USA-Australia comparative policy analysis be undertaken. This analysis would address what constitutes policy and what counts as language planning at local, state and national levels. It is envisaged that such a policy analysis will include policy texts (legislation and public reports), institutional practices and public attitudes as forms of language planning and will examine how community-heritage languages are positioned in these policy processes. The study will also examine the factors that influence resource allocation. It is intended to investigate specifically how policies define the role of schools, families and community institutions in relation to CL-HL development/maintenance and reclamation. The methodology we propose is a combination of ethnographic approaches (including interview and observation techniques); discourse analysis of published texts and key documents; survey questionnaire and other.

\section{Research Recommendation Two}

We propose that a combined ethnographic and quantitative investigation of US and Australian practices of teacher education in community and heritage language programmes be undertaken. This research will analyse a variety of factors and characteristics of the professional pathways of community-heriheritage language teachers. Among these factors will be the educational backgrounds of the teachers, the language proficiency and cultural expertise and knowledge of the teachers, the range of both mainstream and nonmainstream settings in which community and HLE takes place. One of the outcomes of this research will be documentation of exemplar programmes based on a range of different models and settings addressing teacher professional development (pre-service and in-service) and certification (formal and nonformal).

\section{Curriculum/Programmes Group (Christian, de Courcy, Kagan, Mercurio, Scarino)}

To develop a continuum of programme-types for heritage language learning which

- pertains across elementary (possibly also including pre-school), secondary, tertiary;

- accounts for the diversity of languages;

- ranges from language awareness through to two-way bilingual programmes;

- captures the distinctiveness of heritage language learning. 
For each type to include:

- principles of development - addressing issues of ownership etc.;

- variables which pertain to the particular communities;

- ways in which language and culture are addressed including matters such as standard and nonstandard varieties;

- goals, outcomes.

The continuum would be developed drawing upon existing 'successful' programmes with particular consideration given to, for example, stated goals versus enacted goals; anticipated outcomes versus actual outcomes.

\section{Assessment-Census-Survey (Brecht, Campbell, Clyne, Elder, Tucker)}

HL learner profiles and pathways through the educational system: A cross-national study

\section{Objectives}

- To enhance understanding of the linguistic and cultural resources of HL communities in different contexts.

- To provide a basis for the development of educational programmes and instructional strategies which will match these communities' learning needs.

- To establish benchmarks for bilingual development based on empirical evidence from different HL contexts.

\section{Research questions}

(1) What are the patterns of language use/language attitudes and abilities which HL learners bring to the classroom situation? How do these language behaviours/attitudes and abilities differ from those of native speakers in the relevant countries of origin?

(2) What are the perceived language needs (LI and L2) of each HLL community and of the individuals within these communities? What is the gap between needs and baseline behaviours/attitudes and abilities?

(3) What language development opportunities are currently available to HL learners and what pathways do they follow through the educational system?

(4) How do HLL language behaviours/attitudes/abilities (LI and L2) develop in different HLE contexts and at different stages of schooling?

Target HL communities

These questions would be investigated for a series of different languages in both US and Australasian contexts. The following HLL communities have been nominated as potentially worthy of investigation:

- Arabic

- Japanese

- Korean 
- Mandarin

- Russian

- Vietnamese

The study would target a sample of HL learners enrolled in primary secondary and tertiary level HL programmes in mainstream educational contexts as well as in community schools and after hours programmes.

\section{Methodology}

A series of micro and macro analyses of HLL learners and their respective HL communities will be undertaken using a combination of the following:

metanalysis of extant databases (e.g. census, tests, examinations), community surveys;

ethnographies of individual learners at various stages of schooling; and language assessment procedures (including self-assessments) administered longitudinally at various points throughout the schooling system.

Factors investigated will include the following:

- The HLL community both prior to and following immigration (including such factors as history pre- and postmigration, degree of remove from the community where the language is spoken, periodisation, presence or otherwise of diglossia in the community where the language is spoken, varieties of language used (e.g. HL dialects), attitudes to language mixing, parental attitudes to education as well as attitudes to and insistence on language maintenance/development, educational levels, employment patterns).

- The HL learner and his/her place within the family.

- Nature and frequency of HLL's language use both within and outside the home.

- HLL's attitudes to bilingualism and to HL maintenance/development.

- The formal education system in which $\mathrm{s} /$ he is enrolled.

- The HL school/programme.

- Perceived needs (in HL and English).

- Perceived and actual abilities (receptive and productive) in HL (both taught and nonstandard/dialectal varieties) and in English at various stages of schooling.

Possible funding sources

- Ford Foundation (California system).

- Pacific Rim Grant (via the University of Australia Research Council grant and US equivalent).

\section{References}

Brecht, R.D. and Ingold, C.W. (1998) Tapping a national resource: Heritage languages in the United States. ERIC Digest, EDO-FL-98-12.

Campbell, R. and Christian, D. (eds) (2002) Intergenerational transfer of heritage languages. Heritage Language Journal. On WWW at www.heritagelanguages.org. 
Hornberger, N.H. (1989) Continua of biliteracy. Review of Educational Research 59 (3), 271-296.

Hornberger, N.H. (ed.) (2003) Continua of Biliteracy: An Ecological Framework for Educational Policy, Research and Practice in Multilingual Settings. Clevedon: Multilingual Matters.

Hornberger, N.H. and Skilton-Sylvester, E. (2000) Revisiting the continua of biliteracy: International and critical perspectives. Language and Education: An International Journal 14 (2), 96-122.

Hornberger, N.H. and Wang, S.C. (in press) Who are our heritage language learners? Identity and biliteracy in heritage language education in the United States. In D.M. Brinton and O. Kagan (eds) Heritage Language Acquisition: A New Field Emerging. Mahwah, NJ: Lawrence Erlbaum.

Peyton, J.K., Ranard, D.A. and McGinnis, S. (eds) (2001) Heritage Languages in America: Preserving a National Resource. Washington, DC: Center for Applied Linguistics.

Skilton-Sylvester, E. (1997) Inside, outside, and in-between: Identities, literacies, and educational policies in the lives of Cambodian women and girls in Philadelphia. Unpublished PhD, University of Pennsylvania, Philadelphia.

University of California, Los Angeles (2001) Heritage Language Research Priorities Conference Report. Los Angeles, CA: Language Resource Center. On WWW at www.cal.org/heritage.

Wiley, T.G. and Valdés, G. (2000) Heritage language instruction in the United States: A time for renewal. Bilingual Research Journal 24 (4), Entire issue. 